\title{
RACISMO Y DESVALORIZACIÓN DEL TRABAJO DE \\ LAS MUJERES INDÍGENAS EN GUATEMALA: DESDE LA \\ economía doméstica hasta el Caso Sepur Zarco
}

\section{RACISM AND DEVAluATION OF INDIGENOUS WOMEN'S Work in Guatemala: From Domestic Economy to the Sepur Zarco Court Case}

\author{
Patricia Arroyo Calderón ${ }^{*}$ \\ DOI: https://doi.org/10.31644/ED.V7.N2.2020.A04
}

Resumen: El juicio por genocidio contra Efraín Ríos Montt, celebrado en Guatemala en 2013, así como el juicio por el caso de Sepur Zarco, ocurrido en febrero de 2016, colocaron en primer plano la cuestión de la violencia sexual cometida contra las mujeres mayas a escala masiva durante el período más cruento del conflicto armado que se extendió por más de tres décadas en el país centroamericano. En este artículo se abordan los fenómenos de violencia sexual y esclavitud sexual sufridos por, al menos, quince mujeres q'eqchi', entre los años de 1982 y 1988, en paralelo a un aspecto del caso Sepur Zarco que por el momento ha recibido mucha menos atención: el proceso de esclavitud doméstica al que también fueron sometidas por años las mujeres mayas sobrevivientes. En concreto, se propone que los fenómenos de desvalorización del trabajo reproductivo de las mujeres indígenas - manifestado en formas extremas durante el genocidio maya - deben ser entendidos en perspectiva histórica como parte de los procesos de modernización capitalista impulsados

* Afiliación institucional: Assistant Professor del Departamento de Español y Portugués, en la Universidad de California en Los Ángeles, Estados Unidos. Líneas de investigación: historia, literatura y cultura visual latinoamericanas, con enfoque en Centroamérica. Correo-e: parroyo@ ucla.edu.

Fecha de recepción: 04/01/2020. Fecha de aceptación: 29/04/2020. Fecha de publicación: 31/07/2020.

(c)) BY-NC-ND Páginas $94-126$ 
por las élites liberales del istmo desde las décadas finales del siglo XIX, procesos que articularon dos nociones antagónicas (y fuertemente racializadas) de trabajo: el "trabajo productivo" y el "trabajo improductivo". Dichos conceptos, trasladados al ámbito de los hogares centroamericanos, contribuyeron a la consolidación de un renovado orden jerárquico organizado en torno a formas de trabajo doméstico consideradas "productivas" (aquellas labores llevadas a cabo por amas de casa letradas y modernizadas) e "improductivas" (aquéllas completadas por "criadas" indígenas). En última instancia, estos imaginarios de desigualdad en el seno de los hogares siguen manifestándose hoy día en asociaciones naturalizadas entre amplios sectores de la población que equiparan a las "mujeres indígenas" con las "sirvientas", así como en formas de desvalorización, explotación y otros abusos cometidos con impunidad sobre las trabajadoras domésticas del istmo.

Palabras clave: violencia sexual, esclavitud sexual, esclavitud doméstica, economía doméstica, racismo, genocidio, Guatemala, Sepur Zarco.

Abstract: The Guatemalan 2013 genocide trial, where ex-President Efraín Ríos Montt was convicted, and the Sepur Zarco trial held in February of 2016 brought to focus the sexual violence suffered by Maya women at a massive scale during the over-three-decades long civil conflict. In this article, the instances of sexual violence and sexual slavery suffered by —at least-fifteen Q'eqchi' women between 1982 and 1988 are addressed in parallel to a dimension of the Sepur Zarco trial which has been for the most part overlooked: the situation of domestic slavery that was also inflicted on the Maya women survivors. Specifically, I suggest that the process of devaluation of indigenous women's reproductive work (intensified to the extreme during the Maya genocide) needs to be historically understood in relation to the capitalist modernization projects put into motion by Central American liberal elites during the last decades of the 19th century. The liberal modernization projects relied upon two opposing — and heavily racialized - concepts of work: the notion of "productive work" and the notion of "unproductive work." These notions eventually found their way into the Central American households and actively contributed to the creation of a renovated hierarchical order structured around forms of domestic work considered to be "productive" (i.e., 
the domestic work performed by lettered and modernized housewives) and other forms of work considered "unproductive" (that is, the work performed by indigenous domestic servants). Ultimately, these imaginaries of inequality that thrived within the households of the isthmus have survived until today, when ample sectors of the population still equate "indigenous women" with "domestic servants," and when different forms of devaluation, exploitation, and other forms of abuse are inflicted upon local domestic workers with total impunity.

Keywords: sexual violence, sexual slavery, domestic slavery, domestic economy, racism, genocide, Guatemala, Sepur Zarco.

\section{Introducción}

El desarrollo, en 2013, del primer juicio por genocidio contra el general Ríos Montt — donde los testimonios de mujeres ixiles víctimas de violencia sexual tuvieron especial protagonismo- , así como el juicio por el caso Sepur Zarco, que se llevó a cabo en 2016, han contribuido sin duda a situar los debates sobre la violencia sexual como un arma de guerra y como un elemento central en el genocidio de los pueblos mayas de Guatemala ${ }^{1}$. En este sentido, en los últimos años se han producido una serie de reflexiones por parte de las propias mujeres víctimas de violencia sexual, así como por parte de activistas, académicos y otros agentes de la sociedad civil sobre, entre otras cuestiones,

\footnotetext{
${ }^{1}$ El primer juicio por delitos de lesa humanidad y genocidio cometidos contra el pueblo maya ixil, en el cual se sentó en el banquillo de los acusados el expresidente de Guatemala y general del ejército, Efraín Ríos Montt, comenzó en Guatemala en el mes de marzo de 2013 y finalizó con una condena histórica - ya que se trataba del primer juicio por genocidio llevado a cabo contra un exgobernante en un tribunal nacional— de 80 años de prisión, el 10 de mayo de ese mismo año. La sentencia de culpabilidad emitida por el Tribunal de Mayor Riesgo A, presidido por la jueza Yasmín Barrios, fue anulada solamente diez días más tarde por el Tribunal Constitucional que obligó a repetir el juicio alegando defectos procedimentales. Después de múltiples demoras, el juicio se reanudó finalmente, a puerta cerrada, en 2018. A pesar de que en septiembre de ese mismo año el Tribunal de Mayor Riesgo B declaró que sí se había producido un genocidio contra la población maya ixil, ningún acusado fue sentenciado por dicho crimen, ya que Efraín Ríos Montt había fallecido el 1 de abril de 2018 a los 91 años. Más recientemente, en octubre de 2019, ha vuelto a abrirse un nuevo juicio por el genocidio contra el pueblo maya ixil, de nuevo en el Tribunal de Mayor Riesgo B de la Ciudad de Guatemala. En esta ocasión, los acusados son tres altos mandos militares que coordinaron las operaciones del Ejército en esa área del país durante la presidencia del general Fernando Romeo Lucas García (1978-1982).
} 

de las mujeres indígenas en Guatemala...

la naturaleza de la violencia sexual, las formas específicas en la que ésta se ejerció contra las mujeres indígenas, los efectos físicos, psíquicos, espirituales y sociales que esta forma particular de violencia dejó en los cuerpos y en las mentes de las mujeres sobrevivientes (y también en sus comunidades), sobre las trayectorias de las sobrevivientes en el camino hacia la sanación o en su búsqueda de reconocimiento, justicia y reparación. No obstante, la creciente atención prestada a los fenómenos de violencia sexual contra las mujeres mayas también ha llevado a ciertas investigadoras, como Alison Crosby, M. Brinton Lykes y Brisna Cajax (2016) a advertir de los peligros de pasar de un régimen de invisibilidad a uno de "hipervisibilidad" en lo que respecta a los casos de violencia sexual contra mujeres indígenas ${ }^{2}$.

En este artículo se propone, por tanto, un análisis del caso Sepur Zarco desde una perspectiva que no se enfoca en los aspectos de violencia sexual, sino en una dimensión del caso que, por el momento, ha recibido mucha menor atención: el régimen de esclavitud doméstica al que fueron sometidas al menos quince mujeres de la etnia q'eqchi', obligadas durante años a realizar actividades consideradas "reproductivas" (lavar uniformes, cocinar, preparar tortillas, etc.), sin recibir ningún salario a cambio del trabajo realizado.

De acuerdo con los peritajes realizados por la investigadora guatemalteca Marta Elena Casaus Arzú, tanto para el juicio por genocidio contra Efraín Ríos Montt como para el llamado caso Sepur Zarco ${ }^{3}$, el racismo estructural se sitúa como el elemento central que nos puede ayudar a comprender los fenómenos múltiples y complejos de violencia que experimentaron (y siguen experimentando), de forma diferencial, los cuerpos racializados de las mujeres mayas. Al igual que otras antropólogas, como Irma Alicia Velásquez Nimatuj o Rita Laura Segato, quienes también contribuyeron con sus peritajes culturales

\footnotetext{
${ }^{2}$ Véase A. Crosby, M. Brinton Lykes y B. Cajax, “Carrying a Heavy Load” (2016).

${ }^{3}$ Este último peritaje se realizó en colaboración con la antropóloga feminista Marisa Ruiz Trejo. Para un resumen de los aspectos fundamentales presentados en dicho peritaje, véase M.E. Casaús Arzú y M. Ruiz Trejo, Procesos de justicia y reparación.
} 
y de género a los juicios anteriormente mencionados ${ }^{4}$, Casaus y Ruiz Trejo insisten en el vínculo existente entre las violaciones sexuales, la destrucción de los cuerpos de las mujeres indígenas durante el genocidio por medio de atroces mutilaciones y asesinatos y el arrasamiento de comunidades enteras con objeto de impedir la reproducción de la vida. En este sentido, todas las autoras mencionadas coinciden en que las violaciones sexuales fueron un arma de guerra y una herramienta de genocidio contra las comunidades mayas que provocaron, entre otros efectos, malestar psicológico, dolores físicos profundos, enfermedades crónicas, esterilidad, estigmatización o vergüenza entre las mujeres afectadas en el nivel individual, también terror, destrucción, desarticulación social en las comunidades y eliminación de la identidad étnicocultural a escala colectiva.

Como señalan las organizaciones que llevan años acompañando a mujeres indígenas víctimas de violencia sexual durante el conflicto armado ${ }^{5}$, así como investigadoras y activistas como Amandine Fulchirone ${ }^{6}$, Irma Alicia Velásquez Nimatuj, Alison Crosby, M. Brinton Lykes, Brisna Caxaj, Marta Elena Casaus o Marisa Ruiz Trejo, las violaciones sexuales no fueron, en ningún caso, la única forma de violencia experimentada por las víctimas y sobrevivientes. La gran mayoría de ellas quedaron viudas a raíz del secuestro, tortura y asesinato de sus esposos; perdieron sus casas, sus tierras, sus animales, sus cosechas y sus enseres en los procesos de destrucción de sus comunidades; fueron víctimas de violaciones individuales o en grupo (en muchas ocasiones en público y enfrente de sus familiares más cercanos y sus vecinos); fueron víctimas del desplazamiento forzado desde sus casas y aldeas destruidas hacia el destacamento militar donde fueron retenidas para servir de "descanso y

\footnotetext{
${ }^{4}$ La antropóloga maya-k’iche' Irma Alicia Velásquez Nimatuj fue la encargada de realizar el peritaje cultural, mientras que Rita Laura Segato estuvo a cargo de completar el peritaje antropológico cultural de género. Los resultados del peritaje de Velásquez Nimatuj pueden ser consultados en su reciente libro La justicia nunca estuvo de nuestro lado (2019). Por su parte, la función instrumental de la violencia sexual y la violencia extrema sobre los cuerpos de las mujeres en el marco de las nuevas guerras han sido exploradas por Segato en múltiples textos, posiblemente uno de los más significativos Las nuevas guerras y el cuerpo de las mujeres (2014). Buena parte de los argumentos explorados por la antropóloga argentina en dicho texto fueron aplicados al caso concreto de Sepur Zarco durante su peritaje.

${ }^{5}$ Entre otras, ECAP (Equipo de Estudios Comunitarios y Acción Psicosocial), UNAMG (Unión Nacional de Mujeres de Guatemala) y Mujeres Transformando el Mundo.

${ }^{6}$ Véase especialmente el monumental trabajo de recopilación de testimonios de sobrevivientes sometidas a violencia sexual coordinado por A. Fulchirone, Tejidos que lleva el alma (2009).
} 

de las mujeres indígenas en Guatemala...

solaz" para la tropa (esclavitud sexual) y donde fueron forzadas a realizar labores que incluían el lavado de uniformes o la preparación de tortillas para los soldados. Algunas de ellas asistieron impotentes a la muerte de sus hijos por frío, enfermedades, hambre y malnutrición y, finalmente, muchas de ellas fueron víctimas de violencia doméstica, marginación y estigmatización cuando regresaron a sus comunidades, y sufren, desde entonces, situaciones persistentes de pobreza y falta de oportunidades, así como enfermedades y dolores físicos crónicos derivados de sus experiencias traumáticas durante el período de la guerra.

Como puede verse, la violencia sexual fue solamente una de las formas de privación, agresión y destrucción a las que se enfrentaron las mujeres de Sepur Zarco, así como las mujeres indígenas de otras localidades. Algunos testimonios y ciertos análisis del caso Sepur Zarco dan cuenta de las estrechas relaciones que existieron entre la predación de los cuerpos de las mujeres mayas y su agresión por vía sexual y las formas histórico-estructurales de apropiación de la mano de obra y las tierras de las comunidades indígenas en el altiplano de Guatemala ${ }^{7}$. Casaus y Ruiz Trejo evidencian esta interrelación cuando mencionan que "las mujeres [fueron] obligadas a aportar sus relaciones de producción-reproducción en condiciones de secuestro forzado y masivo" (2017), mientras que el peritaje de la antropóloga Rita Segato insiste en la importancia de no desvincular analíticamente los fenómenos de la esclavitud sexual y la esclavitud doméstica, puesto que ambas dimensiones de la experiencia se encuentran unidas de manera inextricable en el horizonte

\footnotetext{
${ }^{7}$ En las páginas que siguen dedicaré mi atención a analizar en detalle solamente la relación entre la predación de los cuerpos de las mujeres indígenas (por vía de la agresión sexual) y la predación de su fuerza de trabajo. No obstante, en el caso concreto de Sepur Zarco, el vínculo entre estas dos formas de violencia contra las mujeres y el despojo de tierras a las comunidades indígenas se evidencia en el hecho de que todas las mujeres sometidas a violencia sexual, esclavitud sexual y esclavitud doméstica eran las viudas de hombres secuestrados, torturados y desaparecidos / asesinados por el ejército de Guatemala a raíz de su participación en los "comités de tierras" locales. De acuerdo al peritaje de Segato, dichos comités habían iniciado "averiguaciones en el Instituto de Transformación Agraria — INTA—, sobre la situación de las tierras que ancestralmente habitaron y cultivaron. Las víctimas querellantes de la causa fueron precisamente las esposas de los hombres detenidos y desaparecidos de la aldea por su intento de reivindicar documentos de posesión estable de la tierra que ocupaban" (2016:18). De igual manera, Casaus y Ruiz Trejo señalan que varias familias pertenecientes a la oligarquía terrateniente facilitaron la construcción del destacamento de Sepur Zarco junto a sus fincas "con el fin de controlar dicha región y vigilar y castigar a aquellos líderes que habían osado formar un comité para solicitar tierras al gobierno" (ídem: 16).
} 
cultural de las mujeres mayas sobrevivientes. El trabajo de Segato detalla cómo la institución del matrimonio se encuentra en el centro de las relaciones sociales de las comunidades q'eqchi'es, dotando de sentido a la existencia social de las mujeres "como nodo en un haz de relaciones productivas y reproductivas (...) en vínculo de reciprocidad en una red familiar y comunitaria” (2016: 12). Estas dobles relaciones — productivas y reproductivas - en el seno del matrimonio implican, para las mujeres q’eqchi'es, "la donación de sus órganos reproductores y su trabajo doméstico" ${ }^{8}$ (ídem: 20). El ejército de Guatemala "rompió" los matrimonios de las mujeres sobrevivientes de Sepur Zarco en un doble sentido: por un lado, al eliminar físicamente (asesinar) a sus esposos; por otro lado, a partir de la expropiación de sus labores productivas y reproductivas, extrayéndolas forzosamente de su contexto de reciprocidad conyugal e intracomunitaria. De esta manera, el peritaje de Segato deja muy claro que "el secuestro de labor doméstica participa de la esfera de sentido de la violación de tipo sexual" (ibídem) ${ }^{9}$.

A pesar de los aportes de Casaus y Ruiz Trejo y del esclarecedor peritaje de Rita Segato, la mayoría de los trabajos disponibles sobre el caso Sepur Zarco —así como, de forma más general, sobre las múltiples formas de violencia ejercidas contra las mujeres indígenas durante el período del genocidio maya - siguen centrándose casi en exclusiva en los aspectos relacionados con la violencia sexual. Varias investigadoras feministas — como Emily Rosser, Allison Crosby, M. Brinton Lykes o Brisna Caxaj- han analizado algunas de las razones que podrían ayudarnos a explicar la "hipervisibilidad" de estos fenómenos en los análisis de las formas de violencia experimentadas por las mujeres mayas durante el conflicto armado. Rosser, en su artículo Depoliticised Speech and Sexed Visibility: Women, Gender, and Sexual Violence in the 1999 Guatemalan Comisión para El Esclarecimiento Histórico Report (2007), señala que este enfoque casi exclusivo en las formas sexuales de la violencia ejercida

\footnotetext{
${ }^{8}$ Mientras que el varón "concurre con su semen y su trabajo en la agricultura" (Segato, 2016: 20).

9 Segato señala que "la esclavitud doméstica, no tiene, para las mujeres q’eqchi'es, el mismo significado que la esclavitud laboral de cualquier otro tipo. El sometimiento en tareas domésticas es sentido como de gran intensidad. Cuando las mujeres relatan su sometimiento sexual y su sometimiento doméstico, lo hacen con idéntica pena, manifestando análoga penuria, y es tan quejosa la referencia al acceso a su cuerpo como al acceso a su trabajo y a sus productos (los alimentos, que ellas eran obligadas a retirar de sus familias para entregar en su servicio a los militares, y el jabón con el que debían lavar sus uniformes)" (2016: 19).
} 

de las mujeres indígenas en Guatemala...

contra las mujeres es inherente a los discursos y las instituciones que operan bajo el paradigma universalista de los "derechos humanos", puesto que "women have been visible in human rights discourse mainly either as generic human beings or (...) as 'sexed bodies' within the framework of rape, victimhood, and embodiment. Vulnerability to sexual violence is a sign of women's difference, or, put another way, women's 'juridical recognisability" 10 (ídem, 398). Allison Crosby y M. Brinton Lykes ofrecen una interpretación similar en su artículo Maya Women Survivors Speak (2011), en el que analizan diferentes procesos de "truth-telling" 11 prestando atención a las implicaciones del marco narrativo dentro del cual suelen insertarse los testimonios de mujeres que sufrieron violencia durante conflictos armados:

Truth-telling processes, in which documentation relies on the personal testimonies of survivors who have been directly or indirectly affected by the violations under consideration, tend to be framed within the liberal language of human rights and emphasize the experience of individuated harm, particularly bodily harm. They also focus on this harm as a particular 'event,' rather than as part of the broader structural relations of power that shape and inform the construction of the subject within her social context [...] Violence produces women victims, the underlying assumptions being that victims are gendered female, that women are all the same and that, within the individuated framework of rights violations and bodily harm, the harm

\footnotetext{
10 "Las mujeres han sido visibilizadas en el marco de los discursos sobre derechos humanos, fundamentalmente en calidad de seres humanos genéricos (...) o bien en calidad de 'cuerpos sexuados' sometidos a procesos de violación, victimización y corporización. Ser vulnerable a sufrir violencia sexual es el signo que marca la diferencia de las mujeres o, dicho de otro modo, la forma en la que las mujeres se vuelven 'reconocibles en términos jurídicos"' [traducción de la autora] (Rosser., 2007: 398).

${ }^{11}$ Podríamos traducir el término "truth-telling" como "dar testimonio" o "relatar la verdad".
} 
experience was sexual violence. Thus, sexual harm is reified as the gendered face of war $^{12}$ (idem, 462).

Las consecuencias de esta reducción de la experiencia de violencia al ámbito de lo corporal e individual han sido, sin duda, variadas. En su dimensión más positiva, han permitido avanzar la lucha por la verdad, la justicia y la reparación en forma de juicios penales, por medio de los cuales - como en el caso Sepur Zarco- se han logrado condenas históricas contra altos mandos del ejército por crímenes de violencia y esclavitud sexual ${ }^{13}$. Pero, en su dimensión negativa, este tipo de aproximación es susceptible de generar

12 "Los procesos de truth-telling, cuya validación recae en los testimonios individuales de sobrevivientes que han sido directa o indirectamente afectados por las violaciones de derechos humanos bajo consideración, tienden a enmarcarse en el lenguaje liberal de los derechos humanos y a enfatizar el daño individual —en particular en lo que respecta al daño corporal—. También entienden este tipo de dańo como un 'acontecimiento puntual' y no como parte de las relaciones de poder estructurales que informan la construcción del sujeto en su contexto social específico [...] La violencia produce mujeres víctimas; las implicaciones que subyacen a esta afirmación es que las víctimas tienen género femenino, que todas las mujeres son iguales y que - dentro de los marcos individualizados de los derechos humanos y el dańo corporal— la violencia experimentada es violencia sexual. Por tanto, el dańo producido por la violencia sexual queda reificado como el único dańo que la guerra provoca en las mujeres" [traducción de la autora] (Crosby y Lyckes, 2011: 462).

${ }^{13}$ La constatación de que las mujeres indígenas habían sido las víctimas principales de los actos masivos de violencia sexual cometidos fundamentalmente por el Ejército de Guatemala - y, en menor medida, por otros actores del conflicto interno- puede rastrearse, al menos, hasta finales de la década de 1990, cuando el informe publicado por la Comisión de Esclarecimiento Histórico (Guatemala: Memoria del silencio, 1999) estipuló que el $89.39 \%$ de las violaciones sexuales reportadas correspondían a casos denunciados por mujeres mayas (frente a un $10.02 \%$ de casos reportados por mujeres ladinas), véase Tomo III, p. 24. Por otro lado, los primeros avances hacia la justicia que se produjeron en Guatemala en relación a las violaciones sexuales masivas perpetradas durante el conflicto armado se dieron en el año 2010, cuando diversas organizaciones feministas facilitaron la labor del Tribunal de Conciencia contra la Violencia Sexual hacia las Mujeres durante el Conflicto Armado en la Ciudad de Guatemala. A raíz de las actividades de este Tribunal de Conciencia, un grupo compuesto por quince mujeres de etnia q'eqchi' decidió presentar una querella penal en 2011. Dicha querella no llegó a juicio hasta el mes de febrero de 2016, cuando el llamado "Caso Sepur Zarco" fue visto en el Tribunal de Mayor Riesgo A de Ciudad de Guatemala. El juicio finalizó con una sentencia condenatoria en contra de los dos acusados - Esteelmer Reyes Girón, ex comandante de la base militar de Sepur Zarco durante los ańos 1980 y Heriberto Valdez Asig, ex comisionado militar- quienes fueron sentenciados a penas de prisión de 120 y 240 ańos, respectivamente. Adicionalmente, el Tribunal decretó medidas de resarcimiento a favor de todas las denunciantes. Para conocer más detalles sobre este proceso, véase el prólogo de Irantzu Hegoa al peritaje cultural de Irma Alicia Velásquez Nimatuj, La justicia nunca estuvo de nuestro lado (2019: 7-11). 
efectos no deseados, en particular, como menciona Zinaida Miller para el caso ruandés, la invisibilización de las cuestiones económicas o bien su equiparación/reducción al problema de las "reparaciones", "background[ing] structural factors in favour of more obvious concerns about physical violence" 14 (2008: 273). Por estas razones, propongo realizar un análisis interseccional e historizado de las diferentes formas de violencia que sufrieron las mujeres indígenas durante el conflicto armado, abordando los fenómenos de violencia sexual, violencia económica y de violenta apropiación de la mano de obra de las mujeres indígenas del período bélico desde una perspectiva histórica de larga duración. En concreto, me interesa destacar las continuidades existentes entre las formas de apropiación de la mano de obra de las mujeres mayas y los imaginarios de "trabajo improductivo" y "cuerpos abyectos" que las élites del istmo centroamericano articularon de forma exitosa y perdurable en las décadas finales del siglo XIX. Dedicaré, por tanto, lo que resta de este texto a explorar, entre otros, los siguientes interrogantes: ¿de qué manera se relacionan las concepciones popularizadas por los reformadores liberales de fines del siglo XIX acerca de la improductividad del trabajo doméstico realizado por "las sirvientas" con los procesos contemporáneos de desvalorización del trabajo de las mujeres indígenas? ¿Cómo perduraron y se metamorfosearon los imaginarios racializados de la improductividad en Guatemala, hasta llegar a nuestros días? ¿De qué manera contribuye la desatención hacia el fenómeno de la esclavitud doméstica como arma de genocidio a perpetuar y naturalizar los imaginarios liberales sobre el trabajo de las mujeres indígenas en la era neoliberal? A mi juicio, solamente cuando logremos desentrañar este resistente constructo imaginario seremos capaces de revertir la desatención con la que se han abordado los fenómenos de esclavitud doméstica producidos en distintos destacamentos militares durante el genocidio de los pueblos mayas en Guatemala.

\section{Amas de casa "productivas" y criadas "abyectas"}

Las tres décadas finales del siglo XIX fueron una era de profundos cambios en Centroamérica, entre otras cosas, puesto que, entre 1870 y 1893 , cada una de las cinco repúblicas centroamericanas experimentó su propia "reforma" o

\footnotetext{
14 "[D]ejando en un segundo plano los factores estructurales en beneficio de preocupaciones más obvias relacionadas con la violencia sexual” [traducción de la autora] (Miller, 2008:273).
} 
"revolución" liberal. Este proceso de reestructuración del poder del Estado y las instituciones a escala regional estuvo a menudo liderado por los miembros de una clase dirigente con fuerte anclaje en la sociedad colonial, pero parcialmente renovada por una serie de familias que se habían enriquecido gracias al café ${ }^{15}$. El nuevo modelo de crecimiento económico, articulado en torno a este cultivo, conllevó la implementación de un conjunto de políticas que cambiarían para siempre el entorno natural, económico y social del istmo. Las revoluciones político-militares fueron inmediatamente seguidas por procesos acelerados y a gran escala de privatización y concentración de tierras, los cuales fueron a su vez acompañados por la liberación de inmensas cantidades de lo que por entonces se denominaban "brazos indígenas". Estos "brazos indígenas" pasaron a integrar el creciente contingente de mano de obra a disposición de un mercado de trabajo en teoría liberalizado, a pesar de que, en la práctica, buena parte de las nuevas formas de contratación fueran subsumidas en viejas estructuras de apropiación del trabajo, tales como el peonaje por deudas o los trabajos forzados.

Las ciencias sociales centroamericanas han dedicado una cantidad considerable de esfuerzo al estudio del papel central de la finca de café en los imaginarios de modernidad de la región. Historiadores y sociólogos de la historia como Elizabeth Dore para el caso de Nicaragua, o Sergio Tischler, Gustavo Palma Murga y Matilde González Izás para el caso de Guatemala, han argumentado de manera convincente que los modelos de organización política instituidos por las élites liberales estuvieron, en buena medida, inspirados por el orden social de la finca ${ }^{16}$. En las fincas cafetaleras, un pequeño número de propietarios mestizos o blancos — una clase compuesta, dependiendo de la región, por inmigrantes europeos o por ladinos locales- dominaron y explotaron brutalmente a una vasta mayoría de trabajadores indígenas (tanto hombres como mujeres y, no en pocas ocasiones, niños), quienes fueron sometidos a formas neocoloniales de organización del trabajo, generando así un régimen de explotación y exclusión que perduró hasta bien entrado el siglo XX.

${ }^{15}$ Véanse M.E. Casaus Arzú, Guatemala: linaje y racismo (1992), y P. Dosal, El ascenso de las élites industriales en Guatemala: 1871-1994 (2005).

${ }^{16}$ Véanse E. Dore, Myths of Modernity (2006); S. Tischler Visquerra, Guatemala, 1944 (1998); G. Palma Murga, Romper las cadenas (2012); y M. González Izás, Modernización capitalista y violencia en Guatemala (2014). 

de las mujeres indígenas en Guatemala...

Si bien el microcosmos de la finca de café ha sido muy bien examinado, no puede decirse lo mismo sobre el universo de los hogares urbanos en el fin de siècle ${ }^{17}$, a pesar de que estas dos unidades económicas y sociales diferenciadas se estructuraron en torno a los mismos conceptos antagónicos de trabajo: un tipo de trabajo concebido como "productivo" vs. otro tipo de trabajo conceptualizado como "improductivo". La teoría del trabajo, originalmente enunciada por Adam Smith, describía la diferencia entre estas nociones del siguiente modo: "Hay un tipo de trabajo que aumenta el valor del objeto al que se incorpora, y hay otro tipo que no tiene ese efecto. En tanto produce valor, el primero puede ser llamado trabajo productivo; y el segundo, trabajo improductivo"18. La distinción acuñada por el economista escocés en 1776 sería aplicada, menos de un siglo más tarde, a un contexto muy diferente por intelectuales latinoamericanos como Domingo Faustino Sarmiento o Juan

${ }^{17}$ Los únicos trabajos que — hasta donde llega mi conocimiento- ponen en relación el universo del trabajo servil desarrollado en las encomiendas coloniales, en las haciendas y en las fincas cafetaleras con las formas históricas de apropiación del trabajo doméstico realizado mayoritariamente por mujeres indígenas son los elaborados por la investigadora kaqchikel Aura Estela Cumes, para el caso de Guatemala (especialmente, su magnífica tesis doctoral titulada La "india" como "sirvienta": servidumbre doméstica, colonialismo y patriarcado en Guatemala). La tesis central de los textos de Cumes seńala que, en este país centroamericano, las estructuras de "ocupación de territorios, expropiación de recursos y medios de vida y despojo de los cuerpos [indígenas que] hicieron posible la vida colonial” (2019: 581) facilitando la reproducción de la vida y de la dominación de los colonizadores españoles - y, posteriormente, de los sectores criollos - generaron un imaginario de larga duración, vigente hasta hoy día, a partir del cual "las mujeres indígenas han sido construidas con una identidad de sirvientas; [mientras que] paralelamente los hombres indígenas son pensados como mozos" (2019: 580). Su enfoque en los orígenes de la "cultura de servidumbre" hace que, lógicamente, los trabajos de Cumes se centren en trazar las continuidades entre el período colonial y la contemporaneidad. Por otro lado, aunque esta autora reconoce la importancia de indagar en las formas en que "la identidad y la condición social de sirvientas que las mujeres indígenas (...) son re-funcionalizadas en la etapa republicana mediante las nuevas lógicas del trabajo forzado" (Cumes 2019: 600), no llega a explorar a fondo las importantes transformaciones que se produjeron en las últimas décadas del siglo XIX en torno a las concepciones sobre el servicio doméstico (el recorrido histórico que Cumes realiza por la etapa comprendida entre el período de la independencia de la región centroamericana y 1944 puede consultarse en La "india" como "sirvienta", pp. 113-125). Mi trabajo se apoya en los excelentes aportes de Cumes y concuerda con sus postulados principales, a la vez que aspira a complementar su estudio en profundidad de "el trabajo doméstico (...) [como] una institución de servidumbre inscrita en lo colonial” (2019: 600) a partir del análisis detallado de las importantes transformaciones que sufrió el trabajo dentro de los hogares centroamericanos en las décadas finales del siglo XIX.

${ }^{18}$ Véase La riqueza de las naciones (1999), Tomo I, Capítulo III. 
Bautista Alberdi, en su empeño por atraer inmigrantes europeos "productivos" al Cono Sur, un espacio cuya heterogeneidad étnica y dependencia económica eran consideradas una rémora para el progreso por parte de estos dos estadistas argentinos ${ }^{19}$. De forma similar a la de sus homólogos del hemisferio sur, las élites centroamericanas comenzaron, en torno a 1870, a asociar la noción de "trabajo improductivo" con las actividades económicas — consideradas desordenadas, caóticas y poco inteligentes - de la población local y, en particular, de la población indígena.

La finca de café fue, sin lugar a dudas, una estructura fundamental de dominación y exclusión en la región centroamericana, pero eso no quiere decir que sea la única unidad económica que merece nuestra atención. Las fantasías de modernidad en Centroamérica fueron edificadas sobre un sólido imaginario, en el cual las diferencias culturales, étnicas y de género equivalían, simplemente, a signos que revelaban una "natural" desigualdad entre grupos sociales. Este imaginario permeó todos los rincones del tejido social y se convirtió en la base de la "gran transformación" que sufrieron los espacios domésticos de las clases medias y altas centroamericanas en el tránsito del siglo XIX al XX ${ }^{20}$. En este sentido, lo que a partir de aquí denominaré "el hogar modernizado" contribuyó de forma importante — junto con la finca de café y la plantación bananera- a la institucionalización de un entramado socio-histórico basado en prácticas de discriminación tanto formales como informales ${ }^{21}$. En el caso concreto de Guatemala, estas prácticas afectaron de forma desproporcionada a la población indígena en general —especialmente en el universo de las fincas agrícolas - y a las mujeres mayas en particular en los "hogares modernizados" de las áreas urbanas-.

\footnotetext{
${ }^{19}$ Véanse F.D. Sarmiento, Facundo (1999) y J.B. Alberdi, Bases y puntos de partida para la organización de la República Argentina (1963).

${ }^{20}$ Para un análisis de las implicaciones materiales del término "gran transformación", véase K. Polanyi, La gran transformación (1989).

${ }^{21}$ Aura Estela Cumes nos llama la atención sobre la importancia de pensar en la casa como "forma política", es decir, "pensarla no exclusivamente como un lugar de trabajo, sino como un núcleo de reproducción de las estructuras de la sociedad" (2019: 602) y, en el caso concreto de Guatemala, también como "espacio de civilización" en el que "se ocultan las historias de desigualdades [...] se normaliza la tutela y se niegan las formas de servidumbre, mientras que se reproducen en los hábitos, en las costumbres y en los discursos reivindicados como modernos" (2014: 395).
} 

de las mujeres indígenas en Guatemala...

En paralelo a la emergencia de estas nuevas estructuras de exclusión, las últimas décadas del siglo XIX presenciaron el surgimiento de un conjunto de nuevas disciplinas que también contribuirían a solidificar esta noción de orden social desigual, según la cual cada cosa tenía que estar en su sitio y cada quien debía permanecer en su lugar ${ }^{22}$. Dos de estas disciplinas ocuparían un lugar protagónico en este empeño: la economía política y la economía doméstica. La urgencia por incorporar los diferentes sectores de la población a actividades orientadas a la producción capitalista condujo a la adopción de estrategias pedagógicas diferenciadas cuyo objetivo era diseminar por todo el istmo centroamericano una serie de conocimientos económicos considerados "modernos". Por un lado, comenzaron a importarse, traducirse y circularse manuales de economía política que ya eran populares en España, Estados Unidos y Francia; por otro, personalidades importantes del mundo académico y político se sumaron al esfuerzo de producir textos de economía política adaptados al medio y las condiciones específicas de Centroamérica. Entre ellos, podemos citar el manual del guatemalteco Lorenzo Montúfar publicado como Apuntes de economía politica en 1887-, quien fue el primer profesor universitario encargado de impartir esta disciplina desde su cátedra en la Universidad de Costa Rica.

Al mismo tiempo que se producía este impulso de diseminación de las ideas económicas liberales entre los varones de las élites letradas, se ponían también en marcha un conjunto de proyectos encaminados a modernizar las prácticas económicas de las mujeres, los artesanos urbanos y la población indígena. Los supuestos en los que se fundamentaban estos proyectos pedagógicos eran bastante similares entre sí, pudiendo reducirse, más o menos, a la siguiente premisa: en el empeño colectivo por acumular capital y lograr el progreso material de la nación, todos los centroamericanos debían contribuir a la creación de riqueza de acuerdo a su posición social particular y a sus habilidades específicas ${ }^{23}$. Para decirlo en palabras de Pilar Larrave, una maestra y escritora de la época: "puesto que la sociedad está compuesta de elementos heterogéneos, necesita del cultivo de cada uno de esos elementos" (1895: 5).

\footnotetext{
${ }^{22}$ Este dicho tradicional, bien extendido a lo largo y ancho de todo el mundo hispano, puede encontrarse frecuentemente en los textos producidos por las élites liberales de fines del siglo XIX que se mencionan en este artículo.

${ }^{23}$ Para un estudio detallado de los procesos de diferenciación educativa en la Guatemala finisecular, véase C. Orellana, Historia de la educación en Guatemala (1997).
} 
Siguiendo esta lógica, muy pronto se creó una densa red de instituciones pedagógicas orientadas a fomentar los conocimientos económicos de las poblaciones indígenas y de las clases populares entre los ańos 1870 y 1883 . En este texto me centraré únicamente en la educación económica de las mujeres centroamericanas. La educación femenina siguió las pautas de diferenciación y especialización que acabo de describir, siendo el vehículo privilegiado para la educación de las mujeres la nueva disciplina de la economía doméstica. De forma similar a lo que había ocurrido con los manuales de economía política, muy pronto comenzaron a importarse manuales de economía doméstica que ya eran populares en los Estados Unidos, España, Francia y Bélgica; algunas de estas publicaciones fueron traducidas y puestas en circulación a través de las instituciones educativas para niñas y señoritas que se estaban fundando en ese momento a lo largo y ancho del istmo ${ }^{24}$. En seguida, otro tipo de formatos culturales empezó también a ocuparse de las materias propias de la economía doméstica; es decir, la correcta gestión o el manejo apropiado del hogar. Entre estas producciones culturales, podemos mencionar un número creciente de artículos publicados tanto en la prensa general como, especialmente, en los dos primeros periódicos escritos por y para mujeres en la región centroamericana ${ }^{25}$, una buena cantidad de artículos de costumbres y, por último, una serie de novelas y obras de teatro sentimentales, dos géneros literarios extremadamente populares en ese período ${ }^{26}$.

El objetivo principal - y común - de este racimo de publicaciones, en especial en lo que respecta a los manuales de economía doméstica, consistía en familiarizar al público femenino con una serie de conceptos fundamentales tales como "valor", "riqueza", "ahorro", "dinero", "capital”, "trabajo productivo" o "trabajo improductivo”, en una forma pragmática y, de ser posible, entretenida.

\footnotetext{
${ }^{24}$ Entre los manuales procedentes de Europa, el libro del español Carlos Yeves sobre Economía doméstica y labores — segunda parte de su volumen El mentor de las niñas_, publicado en 1882, fue uno de los más populares. Por su parte, entre los textos procedentes de Norteamérica, el manual de Florencia (Florence) Atkinson, Economia e higiene doméstica de Appleton, publicado en Nueva York en traducción al castellano en 1888, circuló ampliamente por el istmo centroamericano.

${ }^{25}$ Estos periódicos, de corta vida, se publicaron en Ciudad de Guatemala en la década de 1880 y llevaron por título El Ideal y La Voz de la Mujer.

${ }^{26}$ Algunas de estas publicaciones incluyen textos teatrales de Vicenta Laparra de la Cerda, tales como Tempestades del alma (1896), El ángel caído (1886) o Los lazos del crimen (1886) o sus novelas Hortensia (1896) y La calumnia (1894), así como novelas de otras autoras, como Clementina, o la víctima de un crimen (1890), de Adelaida Chéves.
} 

de las mujeres indígenas en Guatemala...

La autodenominada "ciencia" de la economía doméstica se convirtió también en el vehículo para la articulación de un nuevo sujeto moderno. Voy a denominar a este nuevo sujeto el "ama de casa (centroamericana) productiva", aunque las escritoras de fines de siglo aludían a esta figura de forma bastante más poética, utilizando el término de "el ángel del hogar" ${ }^{27}$. Este ángel un tanto prosaico tenía la obligación de dedicarse en cuerpo y alma a lo que los autores de la época denominaban "el gobierno del hogar" ${ }^{28}$ a partir del despliegue de toda una serie de virtudes económicas diferenciadas en función de su sexo. La más importante de las virtudes económicas femeninas consistía en la capacidad de la mujer de controlar su propio deseo y, como consecuencia de ello, ser capaz de mantener los gastos domésticos bajo un estricto control. El resto de las virtudes del ama de casa económica consistían en su habilidad para manejar el tiempo de una manera productiva, en su aptitud para gestionar de forma eficiente los bienes perecederos y no perecederos de la casa, en su capacidad para controlar las actividades y para disciplinar los cuerpos tanto de sus hijas como de sus criados, y, por último, en su talento para transformar un entorno doméstico de austeridad material en una fuente de placer estético.

Este "ama de casa productiva" fue concebida por los contemporáneos como la pareja por excelencia de lo que Paul Dosal ha denominado "el empresario modernizante centroamericano" 29 , una versión local de lo que teóricos de los procesos de modernización como Karl Polanyi, Albert O. Hirschmann o Michel Foucault han llamado el homo oeconomicus ${ }^{30}$. Este homo oeconomicus u "hombre económico" se convierte en una presencia fantasmagórica en los manuales centroamericanos de economía doméstica, en los cuales raramente aparece; en las escasas ocasiones en las que lo hace, se manifiesta en su propia casa de manera bastante abrupta, irrumpiendo —en palabras de Adelaida

\footnotetext{
${ }^{27}$ El término de "ángel del hogar" apareció por vez primera en 1859 en la novela homónima de la autora espańola Pilar Sinués de Marco, la cual circuló profusamente por todo el continente americano en la segunda mitad del siglo XIX. Para un estudio sobre la circulación y la recepción de El ángel del hogar en América Latina, véase N. LaGreca, Rewriting Womanhood (2009).

${ }^{28}$ Según la terminología utilizada por Carlos Yeves en el primer capítulo de su manual Economía doméstica y labores (1889).

${ }^{29}$ Véase P. Dosal, El ascenso de las élites industriales en Guatemala (2005).

${ }^{30}$ Véanse K. Polanyi, La gran transformación (1989); A.O. Hirschman, The Passions and the Interests (1997); y M. Foucault, The Birth of Biopolitics (2008).
} 
Chéves- "a horas señaladas y casi siempre con urgencia” $(1885,18)^{31}$. En el marco de las narrativas de los manuales de economía doméstica, la función principal de este varón económico consiste en amasar dinero — de forma genérica - en el ámbito público del mercado; no obstante, para que una familia pueda considerarse como una unidad auténticamente productiva, hay toda una serie de actividades económicas que tienen que ser realizadas dentro de los muros del hogar. En este sentido, la riqueza aparece en estos prontuarios de prosperidad económica como un ente precario y volátil que necesita ser defendido activa y constantemente por parte de amas de casa informadas y virtuosas, cuya función principal consiste en transformar el ingreso de su esposo en "capital doméstico", listo para ser puesto al servicio de la reproducción de la familia en forma de consumo productivo (o consumo no suntuario), en forma de preservación y acumulación de todo tipo de propiedad y, por último, en forma de capital reinvertido. Sin este trabajo doméstico minucioso e incesante realizado por las amas de casa productivas, no era posible que se produjera crecimiento económico, puesto que, en palabras de Pilar Larrave, "la riqueza en manos de una mujer sin orden, sin conocimientos prácticos y sin economía, dura lo que dura el sol en recorrer un día en el espacio" (1895: 6) ${ }^{32}$.

La naturaleza productiva del hogar evidenciada por la economía doméstica se convirtió, por tanto, en un asunto de la mayor importancia para las élites liberales ansiosas de situar Centroamérica en el mapa de las naciones modernas y civilizadas. Los diferentes gobiernos liberales de las cinco repúblicas dedicaron considerables esfuerzos al fomento y la extensión de los sistemas públicos de educación para niñas, poniendo un énfasis especial en la transmisión de conocimientos prácticos. Uno de los elementos fundamentales en este empeño fue la materia de "economía doméstica", la cual fue introducida de forma progresiva en los colegios femeninos a partir de 1870: en Nicaragua, las leyes de 1877 instauraron la economía doméstica como asignatura obligatoria; en el mismo año, la maestra y escritora Adelaida Chéves se quejaba amargamente de que no existían suficientes manuales de esta disciplina adaptados a las particularidades centroamericanas; en 1889, la Escuela Normal para Señoritas de El Salvador incrementó el número de horas semanales dedicadas al estudio

\footnotetext{
${ }^{31}$ Adelaida Chéves era una maestra, periodista y escritora guatemalteca que en el año 1885 publicó el manual de economía doméstica titulado La llave de oro.

32 Véase P. Larrave, Economia doméstica (1895).
} 
de tan importante ciencia ${ }^{33}$. En 1890, Ricardo Jiménez — quien por entonces era el ministro de Educación de Costa Rica - anunció solemnemente ante el Congreso de la República que el gobierno tenía previsto inaugurar la primera Escuela Nacional de Economía Doméstica en San José. De acuerdo con el discurso del ministro, este sería un logro de la mayor importancia, puesto que el desempeño correcto de las labores del hogar era uno de los pilares del crecimiento económico de la nación:

si [la mujer] no sabe ser hacendosa, la felicidad doméstica no puede existir [...] y si el dinero que un hombre entrega a su mujer, fruto de su cuotidiano [sic] trabajo, no aumenta en manos de ella su valor mediante el atinado empleo y el ahorro, la miseria se apoderará a la postre de aquel hogar. Una casa sin gobierno es un buque en naufragio ${ }^{34}$.

Con el objeto de cumplir con tan crucial misión, el gobierno costarricense había destinado un sustancial presupuesto para trasladar hasta este país centroamericano a un grupo de maestras europeas formadas en el sistema belga de las Écoles Menagères.

A partir de las reflexiones anteriores, quisiera enfatizar tres puntos. En primer lugar, desde la década de 1870, el trabajo doméstico dejó de ser concebido como una labor secundaria y natural que cualquier mujer pudiese llevar a cabo de forma idiosincrática o siguiendo sus propios instintos, y pasó a ser considerado un asunto muy serio que debía conllevar una formación reglada e impartida en instituciones especialmente capacitadas para ello. En segundo lugar, los proyectos de modernización impulsados por los Estados centroamericanos concibieron el hogar como otra de las esferas que debía quedar absorbida y reestructurada bajo las mismas lógicas liberales de la productividad y la acumulación de capital, lógicas que, en última instancia, debían impulsar a la región en su marcha hacia la civilización y el progreso material. Bajo estos parámetros, el "ama de casa productiva" era un agente económico tan importante como el "empresario modernizante" y, por lo tanto, el incremento de las ocupaciones domésticas de las amas de casa a fines de

\footnotetext{
${ }^{33}$ Para un análisis en profundidad de las reformas que afectaron a la educación de las mujeres en Nicaragua, véase I. Rodríguez Rosales, La educación durante el liberalismo (1998); para el caso de El Salvador, véase O. Vásquez Monzón, Mujeres en público (2014).

${ }^{34}$ Véase la Memoria de Instrucción Pública (1890: 13).
} 
siglo no debe ser interpretado como un símbolo de la persistencia de modelos anticuados o regresivos de domesticidad, sino más bien como el signo del advenimiento de la modernidad capitalista al espacio del hogar. Por último, los discursos hegemónicos que estoy analizando aquí construyeron tanto la subjetividad como el cuerpo del "ama de casa productiva" por oposición a las subjetividades y los cuerpos de dos arquetipos femeninos diferenciados que terminarían por ser considerados la némesis anti-económica del ama de casa burguesa. Estas contrafiguras femeninas serían, por un lado, la esposa ociosa y despilfarradora y, por otro, la sirvienta improductiva y abyecta.

De esta manera, a la altura de 1900, la noción de "trabajo doméstico productivo" había sido atribuida en exclusiva a la figura del ama de casa modernizada y económica. Su plus de productividad provenía directamente del tipo de formación especializada en materias de economía, higiene, contabilidad o pedagogía que recibían estas amas de casa letradas y semiprofesionalizadas a través del estudio de la "economía doméstica" — una disciplina básicamente de índole miscelánea- Todas las mujeres, con independencia de su estatus social, debían saber cómo realizar correcta y eficientemente "los trabajos de su sexo" con objeto de "exigir el mejor modo de que se los hagan [...] enseñarlos a sus hijas si las tiene o a sus mismas sirvientas" ${ }^{35}$. La educación y supervisión adecuada de los criados y, en especial, de las sirvientas, se convirtió así en una de las responsabilidades principales de la esposa a cargo del hogar ya que —en palabras de las historiadoras feministas Barbara Ehrenreich y Deirdre English— "housework was becoming too scientific and complex to be performed by uneducated women anyway" 36 .

Como contraparte a este constructo imaginario que he denominado el "ama de casa productiva", la expansión por Centroamérica de la noción de "trabajo doméstico improductivo" coincidió, a fines del siglo XIX, con la emergencia de un agrio debate público en torno al "problema del servicio". Este debate generó una profusión de materiales culturales de todo tipo, incluyendo artículos periodísticos, fotografías y cuadros de costumbres, algunos de ellos escritos por intelectuales y políticos de primera fila como José Milla y Antonio

\footnotetext{
${ }^{35}$ Véase P. Larrave, Economía doméstica (1895), p. 21.

36 "El trabajo doméstico se estaba convirtiendo en algo demasiado científico y complejo como para ser llevado a cabo por mujeres sin educación” [traducción de la autora]. Véase B. Ehrenreich y D. English, For Her Own Good (2005), p. 183.
} 

de las mujeres indígenas en Guatemala...

Batres Jáuregui ${ }^{37}$. Las aceleradas políticas de redistribución y acumulación de tierras, así como la disolución de buena parte de las comunidades indígenas de la región liberaron un gran número de sujetos que pasaron a engrosar las filas del mercado de trabajo asalariado. Como ya hemos visto, muchos de estos trabajadores fueron absorbidos por las grandes fincas de café; otros, especialmente las trabajadoras indígenas, se integraron en los circuitos ya racializados- del servicio doméstico en hogares urbanos. En seguida comenzaron a llover los ataques lanzados por las élites letradas —algunos de ellos extremadamente agresivos - en contra de las habilidades laborales, la moral e, incluso, los cuerpos de las trabajadoras domésticas por cuenta ajena. En un cuadro de costumbres titulado, justamente, Las criadas (1882), José Milla ofrecía su interpretación de las nuevas condiciones estructurales bajo las cuales se ejercía a fines de siglo el trabajo doméstico remunerado. Después de expresar su nostalgia por los antiguos "buenos tiempos" del hogar quasi-colonial de su padre, donde las criadas "nacidas en casa" eran decentes, cariñosas y prácticamente parte de la familia, pasa a expresar su frustración por la "situación doméstica" que se encuentra al regresar de uno de sus múltiples viajes al extranjero:

Cuando regresé de un largo viaje a Europa, encontré las cosas completamente cambiadas. [Habíamos] entrado de lleno en el nuevo régimen. [...] En otro tiempo, estaba establecido entre la servidumbre el sistema de la inmovilidad; hoy, van rodando los cargos entre todas las ciudadanas, como debe suceder en un buen sistema republicano. Cada dos meses, cada quince días y aun algunas veces más frecuentemente, hay domésticas nuevas ${ }^{38}$.

\footnotetext{
${ }^{37}$ José Milla y Vidaurre (Guatemala, 1822-1882), quien publicó parte de su obra bajo el nom de plume de Salomé Jil, fue un hombre de estado, diplomático, periodista, historiador, novelista y escritor de libros de viajes y cuadros de costumbres que ocupó un espacio central en la vida cultural y literaria centroamericana de la segunda mitad del siglo XIX. Por su parte, Antonio Batres Jáuregui (1847-1929), también guatemalteco, ocupó diversas posiciones en el gobierno de Guatemala entre las décadas de 1870 y 1890 —diplomático y ministro de Relaciones Exteriores-y formó parte de diversas sociedades científicas centroamericanas. Escribió artículos de costumbres, libros de viajes, guías para inmigrantes y ensayos pioneros en las emergentes disciplinas de la filología y la antropología.

${ }^{38}$ Véase J. Milla, Las criadas (1882), p. 175.
} 
Evidentemente, el escritor guatemalteco consideraba que las recientes convulsiones políticas habían pasado factura al idílico orden doméstico de raigambre colonial. Justo a continuación, Milla se enzarza en una crítica feroz de las nuevas ocupantes de la casa:

Mi actual cocinera se llama Simona... La Simona dice que ha sido cocinera solo de casas grandes. [...] Y, sin embargo, el caldo que nos pone en la mesa pudiera servir para bautizar con él [...]. El arroz bien podría, en caso necesario, suplir la falta de perdigones. Me dirás que, ¿por qué no despedimos a esta alhaja? Porque cambiarla sería tal vez solo variar de nombre y tener, en lugar de una viuda apócrifa, una casada problemática. [...] La de adentro se llama Pioquinta [...] Los oficios de la doméstica que ocupa ese empleo se reducen a barrer y limpiar las habitaciones, y hacer los mandados. La Pioquinta barre en mi casa cuanto encuentra, aunque no sea basura, y limpia hasta lo que no está sucio. Tiene la manía de emplear horas de horas en los recados, viniendo así a suceder que la de adentro es la criada más de afuera de las que tenemos (ibídem: 176).

José Milla sigue y sigue con su diatriba, criticando a la modista, a la nodriza e incluso a su mejor amigo por haber tenido la idea de sugerirle que escribiera un artículo de costumbres sobre el problema de las criadas. Notoriamente molesto, decide concluir su texto con las siguientes palabras: "No sé qué puede decirse de ellas que merezca la pena ser leído" (ídem: 178).

Lo que quiero resaltar con estas citas es que la súbita liberación de una gran cantidad de mano de obra indígena en el mercado laboral urbano, en combinación con los niveles crecientes de profesionalización y regulación que demandaban las tareas domésticas en los hogares modernizados, fueron la causa que provocó un intenso y acelerado proceso de devaluación simbólica y material del trabajo doméstico remunerado realizado por las criadas. Ahora, el ama de casa modernizada debía "saber" cómo llevar una casa mucho mejor que sus criadas, al igual que debía tener un mejor conocimiento de cómo realizar de manera eficiente cualquier tarea doméstica de índole productiva. A mi juicio, lo que podemos observar en este período es la abrupta sustitución de las viejas jerarquías domésticas de raigambre colonial, cuyas lógicas de desigualdad se basaban en el linaje y el estatus, por una nueva estructura 

de las mujeres indígenas en Guatemala...

piramidal edificada en torno a las nuevas lógicas del "trabajo productivo" vs. el "trabajo improductivo". En este sentido, y de forma similar a lo que había ocurrido en las fincas cafetaleras, los imaginarios de modernidad en Centroamérica funcionaron como una bisagra que reproducía las estructuras de dominación, desigualdad y exclusión propias de la colonia, al tiempo que transformaba radicalmente las lógicas a partir de las cuales se legitimaba la dominación, la desigualdad y la exclusión social.

A pesar de que los materiales escritos durante esta época tienden a obliterar la cuestión de la etnicidad de las criadas, el registro fotográfico nos confirma que esta forma devaluada de trabajo doméstico era realizada, en su mayor parte, por mujeres indígenas y, en ocasiones, también por mujeres afrodescendientes ${ }^{39}$. También sabemos que, de forma similar a lo que estaba ocurriendo en las fincas, las nuevas condiciones de trabajo doméstico —en teoría móvil y asalariado - se fusionarían muy a menudo en la práctica con formas neocoloniales de servidumbre tales como la figura de "los hijos de casa”, una forma peculiar de semi-esclavitud doméstica que sobreviviría hasta bien entrado el siglo $\mathrm{XX}^{40}$.

\footnotetext{
${ }^{39}$ Desafortunadamente, los ricos archivos fotográficos guatemaltecos de fines del siglo XIX han sido aún poco explorados, aunque existen notables excepciones, como el sugerente artículo de Greg Grandin Can the Subaltern Be Seen? Photography and the Affects of Nationalism (2004), un texto en el que el historiador norteamericano explora la construcción de subjetividades, así como las formas de construcción de una fuerte identidad k'iche' en Quetzaltenango a partir del análisis de una serie de retratos de estudio encargados por miembros de la población indígena local al fotógrafo Tomás Zanotti durante la década de 1890. Fotógrafos locales como Alberto Valdeavellano o Emilio Herbruger y expediciones fotográficas internacionales como la organizada por el Museo de Etnología de Hamburgo a inicios del siglo XX- dejaron constancia visual de las nodrizas, lavanderas y otras empleadas domésticas de este período en colecciones de imágenes en las que registraron los profundos cambios estructurales, sociales y culturales que se produjeron en este periodo.

${ }^{40}$ Por "hijos de casa" se entienden los menores que, bien por haber quedado huérfanos, o bien por proceder de familias tan humildes que no pueden hacerse cargo de su manutención, son entregados a familiares lejanos o a desconocidos para ser criados "en casa". Generalmente, los menores mencionados reciben comida y alojamiento (en ocasiones en condiciones infrahumanas) a cambio de realizar todo tipo de labores domésticas no remuneradas para su familia de acogida. Para una ficcionalización (excelentemente documentada) de las condiciones de vida de un "hijo de casa" en la década de los años 1950 en Guatemala, véase la novela de Dante Liano, El hijo de casa (2004). La propia Rigoberta Menchú relata, en su célebre testimonio Me llamo Rigoberta Menchú y asi me nació la conciencia (1982), cómo su padre, por las condiciones de pobreza de su familia, fue criado como "hijo de casa" o menor "regalado" durante la década de 1960 .
} 
Todos estos materiales visuales y textuales contribuyeron a que las representaciones de los cuerpos de las criadas racializadas comenzaran a sufrir dos procesos simultáneos: un proceso de exotización, por un lado, y un proceso paralelo de desacreditación, por otro. En concreto, buena parte de los ataques quedaron adheridos a los cuerpos de las nodrizas y las lavanderas, sobre las cuales las élites letradas liberaron sus ansiedades en torno a los contactos interraciales, las enfermedades y los procesos de contagio. Las expertas centroamericanas en economía doméstica afirmaban que el contacto o la cercanía física con las lavanderas era inherentemente peligroso porque "las personas entregadas a esa profesión no toman ningunas precauciones, contrayendo enfermedades fatales y contagiosas y, por lo tanto, no inspiran ninguna confianza” ${ }^{\not 1}$. También estaban convencidas de que emplear los servicios de nodrizas y niñeras ponía en peligro a los bebés, puesto que los entregaba "en manos mercenarias, quizá inmorales, tal vez criminales, que lejos de cuidarlos los abandonan" ${ }^{42}$. Al mismo tiempo, fotógrafos locales como el guatemalteco Alberto Valdeavellano y expediciones científicas europeas, como la organizada por el Museo de Etnología de Hamburgo alrededor de 1900, dedicaron considerables esfuerzos a fotografiar el universo de las criadas indígenas: las imágenes que produjeron circularon tanto en los mercados locales como internacionales, ávidos de consumir representaciones visuales de sujetos "primitivos" en la poco amenazadora forma de cartes de visite, tarjetas postales y exhibiciones fotográficas. Podemos decir, por tanto, que, a principios del siglo XX, el imaginario sobre el abominable cuerpo de la criada "improductiva", "primitiva" y "abyecta" estaba ya vivo y coleando.

\section{Reflexiones finales: La persistencia de los imaginarios racializados del "trabajo improductivo"}

El problema que se nos presenta a raíz de estas apreciaciones tiene, sin embargo, más urgencia de lo que pudiera parecer a simple vista. El problema real al que nos enfrentamos es que estas lógicas a partir de las cuales se justificó y legitimó la degradación, el vilipendio y la explotación de las trabajadoras domésticas asalariadas todavía están vivas y coleando en la Centroamérica del siglo XXI. Como contaba en 2013 Ana Gladis Sibrián —una trabajadora

\footnotetext{
${ }^{41}$ Véase A. Cheves, La llave de oro (1887), p. 86.

${ }^{42}$ Véase P. Larrave, Economia doméstica (1895), p. 96.
} 

de las mujeres indígenas en Guatemala...

doméstica salvadoreña de 50 años — al ser entrevistada por la documentalista Marcela Zamora, cuando se acerca la hora del almuerzo: "Yo de mi casa me llevo mi plato, me llevo mi vaso, porque hay partes en que a una le tienen asco [...] Yo fui a una casa en la que la comida mejor la botaban a los perros". Un día, Ana Gladis reunió el coraje suficiente para preguntarle a su patrona si podía llevarse algunas sobras a su casa, y recibió la siguiente contestación: "La del perro es [del] perro, me dijo, y es mejor que tu comida" ${ }^{43}$. Desde Guatemala, la investigadora kaqchikel Aura Estela Cumes nos recuerda que la "cultura de servidumbre" está aún tan enquistada en la región que cualquier mujer indígena que pasee por las calles de Ciudad de Guatemala corre el riesgo de ser inmediatamente considerada una sirvienta o "muchacha" ${ }^{4}$. Académicas como Marta Casaus o Diane Nelson han analizado cómo las mujeres indígenas que adquieren una presencia relevante en la esfera pública, como ha sido el caso de Rigoberta Menchú o Rosalina Tuyuc — por citar solamente dos ejemplos muy conocidos- suelen convertirse en la diana de insultos tales como "india igualada" o "cholera" que provienen directamente del modelo opresivo y desigual de domesticidad que se ha descrito en este artículo ${ }^{45}$. Estas mismas mujeres indígenas tienden a ser también el objetivo de chistes repetidos hasta la saciedad, cuya supuesta gracia radica en la asunción socialmente compartida de que el lugar que les corresponde es limpiando una

\footnotetext{
${ }^{43}$ El testimonio de Sibrián puede verse en el documental Las muchachas, dirigido por Marcela Zamora en 2013.

${ }^{44}$ Véase A.E. Cumes, Cultura de servidumbre y trabajo en casa particular (2014). A su vez, en su texto La "india" como "sirvienta" (2019), Cumes señala que "en el imaginario social cuando se piensa en trabajadora de casa particular, se piensa en sirvienta, y cuando se piensa en sirvienta se piensa en una mujer indígena mucho más que en una mujer pobre, aunque no todas las trabajadoras de casa son indígenas, ni todas las indígenas son trabajadoras de casa” (2019: 579), para más adelante añadir que "[i]maginar a las mujeres indígenas como sirvientas, llamarlas 'maría' y ofrecerles empleo doméstico en la calle refleja el funcionamiento de esta institución de servidumbre" (2019: 601).

${ }^{45}$ Véanse M.E. Casaus Arzú, Linaje y racismo (1992) y D. Nelson, Gendering the Ethnic-National Question (1999).
} 

las mujeres indígenas en Guatemala...

casa ajena ${ }^{46}$. Este proceso de "basurización simbólica" ${ }^{77}$ se encuentra reforzado por instituciones y regulaciones como los códigos de trabajo vigentes en varios países de la región. Estos códigos conciben a las trabajadoras domésticas por cuenta ajena como una suerte de "no-trabajadoras", por lo cual se encuentran privadas de una serie de derechos básicos de los que, al menos sobre el papel, sí gozan otro tipo de empleados. Jornadas laborales con un límite de horas,

\begin{abstract}
${ }^{46}$ Este proceso no es en absoluto exclusivo de Guatemala y tiende a replicarse en contextos étnica y culturalmente heterogéneos en los que, históricamente, la población indígena ha ocupado espacios sociales considerados subalternos - y en los que los espacios profesionales del trabajo en casa ajena, por tanto, se hallan fuertemente racializados-. Podemos encontrar notables ejemplos recientes en el caso de México, donde la candidata a la Presidencia de la República en las elecciones de 2018, María de Jesús Patricio Martínez (más conocida como "Marichuy"), recibió insultos constantes durante su campańa por el mero hecho de ser una mujer nahua. Más recientemente, la actriz Yalitza Aparicio fue la diana de múltiples ataques racistas después de que su actuación en el filme Roma (Alfonso Cuarón, 2018) —en el cual Aparicio interpretaba a Cleo, una empleada doméstica mixteca en la Ciudad de México a inicios de los 1970_ fuese nominada a un buen número de premios nacionales e internacionales (incluyendo el Ariel y el Óscar a la mejor actriz). De entre los comentarios ofensivos que la actriz oaxaqueña recibió durante la campaña de promoción de la película, quizá los más reveladores fueron los que emitió el también actor Sergio Goyri quien, después de calificar a Yalitza Aparicio como "pinche india", se mostró incrédulo ante el hecho de que una actriz indígena pudiera ser nominada a diversos premios por decir "Sí, señora; no, señora”. Además del evidente y burdo racismo explícito del comentario, lo que Goyri reveló con sus palabras es el hecho de que buena parte de la sociedad mexicana aún asocia automáticamente a las mujeres indígenas con el trabajo doméstico por cuenta ajena, hasta el punto de que el trabajo de una actriz indígena que "representa" en la pantalla a una empleada doméstica se convierte en pura redundancia puesto que — según esta lógica — cada mujer indígena es, en esencia, una criada. Finalmente, me gustaría comentar el caso de la caricatura publicada en el diario El Heraldo con motivo de la visita a México de la líder maya Rigoberta Menchú. En dicha caricatura se representaba al expresidente Enrique Peña Nieto y su esposa, Angélica Rivera, llegando a la residencia de Los Pinos con Rigoberta Menchú. Allí, la ex primera dama de México, visiblemente agotada, comenta mientras se descalza en un sofá: "Aún no entiendo por qué tuvimos que ir tan lejos por una señora que nos va a hacer la limpieza". Todos estos casos fueron ampliamente debatidos en la prensa y las redes sociales - tanto en el seno de México como fuera del país - y revelan la persistencia y la extensión de los prejuicios y los estereotipos negativos asociados con el servicio doméstico racializado.

${ }^{47}$ Este concepto fue acunado por la poeta, periodista y crítica cultural peruana Rocío Silva Santisteban en su libro El factor asco (2008), donde analiza esta emoción "culturalmente construida" como una herramienta al servicio del autoritarismo y la construcción de diferencias sociales naturalizadas. Para esta autora, el asco y sus diferentes formas de "basurización simbólica” son unas potentes armas para apuntalar regímenes basados en una fuerte exclusión social —y/o en el exterminio de ciertos sectores de la población — ya que deshumanizan al Otro a partir de movilizar un afecto "profundamente primitivo, nuclear, animal" (2008: 12).
\end{abstract}



de las mujeres indígenas en Guatemala...

un día libre a la semana, vacaciones pagadas; ninguno de estos derechos está vigente para las trabajadoras domésticas de la región ${ }^{48}$. Adicionalmente, por desgracia, en muchos hogares centroamericanos se sigue produciendo una correlación entre la extrema devaluación del trabajo doméstico asalariado, los procesos de abyectificación o basurización de los cuerpos y las vidas de las trabajadoras domésticas por cuenta ajena, y la continuada persistencia de abusos sexuales contra las "sirvientas", consideradas objetos susceptibles de ser usados y desechados ${ }^{49}$.

Como puede verse a partir de los ejemplos ofrecidos, la devaluación del trabajo doméstico y reproductivo realizado por las mujeres mayas, imaginadas como las "criadas de la nación", ha ido históricamente acompañada de los fenómenos de apropiación de mano de obra indígena y de la abyectificación y basurización de los cuerpos y las vidas de las mujeres (mayas) dedicadas al servicio doméstico. Asimismo, los fenómenos descritos han ido también de la mano de la exotización y la conversión en objetos sexuales de las mujeres dedicadas profesionalmente a esta labor, convirtiendo los hogares centroamericanos en espacios en los que los abusos y la violencia sexual contra las "criadas" se encuentran completamente naturalizados y gozan

\footnotetext{
48 A pesar de que, en los últimos años, organizaciones de trabajadoras domésticas como ATRAHDOM (Asociación de Trabajadoras del Hogar a Domicilio y de Maquila, Guatemala), Astradomes (Asociación de Trabajadoras Domésticas, Costa Rica y Nicaragua) o la Red de Trabajadoras Domésticas de Honduras - entre otras asociaciones presentes en la regiónhan conseguido lograr algunos avances legislativos importantes (además de visibilizar las problemáticas específicas de las trabajadoras domésticas por cuenta ajena), aún queda mucho camino por recorrer a la hora de equiparar los derechos laborales de las empleadas domésticas con los de los y las trabajadoras de otras profesiones.

49 Es posible encontrar abundantes descripciones en conocidas novelas de autores centroamericanos contemporáneos en las que se observa de forma muy clara este proceso simultáneo de abyectificación y sexualización de los cuerpos de las trabajadoras domésticas. Uno de los más notorios aparece en la celebérrima novela del autor salvadoreńo Horacio Castellanos Moya, El asco. Thomas Bernhard en San Salvador (1997). En este texto, Castellanos Moya pone en boca de Edgardo Vega —el amigo de Moya, alter ego del autor y narrador de la novela - una diatriba en contra de la empleada doméstica de su hermano, sobre la cual vierte alrededor de cuatro páginas de puro vitriolo: después de acusarla genéricamente de "robar", se pregunta cómo su hermano - y empleador — puede sentirse atraído sexualmente por ella; a partir de esta constatación, Vega ofrece el lector toda una serie de vívidos detalles acerca de lo que él describe como el nauseabundo olor de la empleada, su sudor, la grasa que — según él— constantemente exhala y hasta las venas varicosas que recorren sus piernas.
} 
de una impunidad generalizada ${ }^{50}$. Es precisamente sobre estos imaginarios naturalizados de desigualdad —así como sobre las históricas prácticas de discriminación relacionadas con las identidades, los cuerpos y el valor del trabajo de las mujeres mayas - sobre los que se apoyaron el estado y el ejército de Guatemala a la hora de cometer algunas de las violaciones de derechos humanos más atroces contra las mujeres indígenas durante el pico de violencia genocida a inicios de los ańos ochenta. Estos actos de violencia implicaron un salto de dichos imaginarios y prácticas desde la esfera "íntima” de los hogares a los espacios institucionales del ejército (en especial, los destacamentos militares) y se manifestaron en formas colectivas de esclavitud sexual, esclavitud doméstica y privación de la vida como las que relataron las quince mujeres

\footnotetext{
${ }^{50}$ De forma similar a la presencia de fenómenos de "basurización simbólica" de las empleadas domésticas en la producción cultural contemporánea centroamericana, también podemos encontrar ejemplos de naturalización del abuso sexual en el marco de las relaciones entre patrones y empleadas en textos y filmes producidos en la región. Un claro ejemplo puede encontrarse en el filme El silencio de Neto (Argueta, 1994), una de las primeras películas centroamericanas de ficción en recibir atención internacional —además de gozar en su día de un importante éxito de público-. El filme de Luis Argueta está ambientado durante el golpe de estado de 1954 contra Jacobo Árbenz y se centra en el proceso de maduración acelerada de Ernesto "Neto" Yepes, un niño de buena familia, pero tímido, con asma y algo de sobrepeso. A pesar de que no se sitúa en el centro de la narrativa, una de las subtramas de la película se enfoca en la relación entre Rodrigo, el hijo mayor de la familia, y Nidia, una joven empleada doméstica indígena. Las imágenes en pantalla — que con frecuencia muestran a Rodrigo forzando a Nidia a mantener relaciones íntimas con él en las dependencias de la casa destinadas a la servidumbre - son incómodas, sin duda, para un espectador contemporáneo sensibilizado con la violencia de género; a pesar de ello, el filme trata dichas escenas con gran naturalidad, presentándolas como una bella historia de amor interétnica e interclasista que solamente se ve frustrada por la muerte de Rodrigo como consecuencia de su militancia política pro-arbenzista.
} 

de las mujeres indígenas en Guatemala...

q'eqchi' que ofrecieron su testimonio sobre los terribles sucesos acaecidos en el destacamento de Sepur Zarco entre 1982 y $1988^{51}$.

Me gustaría concluir este texto con una breve reflexión acerca de algunas de las posibilidades que pueden abrirse a partir de la incorporación más exhaustiva de los fenómenos de esclavitud doméstica a los análisis de casos concretos, como el de las graves violaciones a los derechos humanos de las mujeres q'eqchi' que se produjeron en el destacamento de Sepur Zarco. A mi juicio, la integración de las dimensiones de la esclavitud y la violencia sexual con el aspecto repetitivo de la explotación del trabajo reproductivo de las mujeres mayas en turnos no remunerados permitiría, por un lado, enfatizar

${ }^{51}$ Por supuesto, esta no es la única explicación posible. En su peritaje sobre el caso Sepur Zarco, Rita Segato señala que las formas extremas de violencia desplegadas contra las mujeres mayas, así como las formas específicas en las que se desarrollaron los fenómenos de esclavitud sexual y esclavitud doméstica en el destacamento militar contiguo a la comunidad q'eqchi' de El Estor, estuvieron encaminadas a destruir "los cimientos que sustentan y mantienen cohesa $[$ sic $]$ esa sociedad" a partir de "[l]a utilización de símbolos de este arraigado y ancestral imaginario" y del despliegue de "coreografías de agresión dirigidas con precisión quirúrgica y cálculo perfecto al centro de gravedad del edificio maya" (2016: 23). En este sentido —y como ya se ha explicado anteriormente- las prácticas de esclavitud sexual y esclavitud doméstica habrían estado encaminadas a humillar y estigmatizar a las mujeres de las comunidades atacadas, rompiendo las relaciones recíprocas de producción-reproducción propias y exclusivas de la unidad conyugal, unidad que a su vez funge como fuente de la existencia social de las mujeres y como pilar de la estructura comunitaria q'eqchi'. Creo que el enfoque de Segato -que privilegia el conocimiento por parte del ejército de Guatemala de las especificidades culturales y las estructuras internas de funcionamiento de las comunidades mayas atacadasy el que yo presento en este artículo — que enfatiza la persistencia a lo largo de la historia de Guatemala del imaginario construido en torno al trabajo realizado por las mujeres mayas en el ámbito doméstico como un trabajo "sin valor"- no son, en absoluto, mutuamente excluyentes sino, más bien, complementarios. No en balde, los estudios históricos disponibles sobre trabajo doméstico y cultura de servidumbre señalan que, en la Guatemala colonial y republicana, ciertas formas de explotación y apropiación del trabajo doméstico realizado por mujeres indígenas llegaron a poner en peligro la capacidad de reproducción de las comunidades mayas (véase, en especial, el modelo de "vampirismo" criollo elaborado por Marco Chivalán en su estudio sobre las nodrizas indígenas en el siglo XVIII). Por otro lado, no es ninguna novedad señalar que el conocimiento antropológico — desde sus albores a fines del siglo XIX — se ha puesto frecuentemente al servicio de proyectos de exterminio biológico y cultural de los pueblos estudiados por dicha disciplina. En el caso que nos ocupa, podemos observar el maridaje entre los imaginarios racistas acerca del trabajo de las mujeres mayas y el conocimiento profundo de las estructuras sociales y culturales del pueblo q'eqchi' puestos, simultáneamente, al servicio del proyecto genocida del ejército de Guatemala. Evaluar si alguno de estos elementos tuvo más impacto que el otro en los procesos de destrucción de las comunidades mayas durante el genocidio excede con mucho las pretensiones de este artículo. 
las dimensiones materiales de la violencia sufrida por las mujeres mayas durante el conflicto, así como visibilizar explícitamente la dimensión del valor económico generado por el trabajo de las mujeres indígenas, apropiado por la institución del ejército y sustraído a ellas mismas, sus familias y sus comunidades. En segundo lugar, el análisis integrado de las agresiones de índole sexual y las agresiones de índole material facilitarían el reconocimiento de las continuidades históricas de la violencia contra las mujeres mayas, un aspecto que las propias sobrevivientes — como señalan Crosby, Brinton Lykes \& Caxaj (2011) en "Carrying a Heavy Load”- están demandando en diversos foros. Finalmente, estos análisis cruzados permitirían imaginar, trazar y trenzar líneas de conexión y solidaridad entre movimientos aparentemente distantes y dispares — y, sin embargo, estrechamente relacionados - como las luchas por la verdad, la justicia y la reparación y en contra de la impunidad, y las luchas por el reconocimiento del valor del trabajo doméstico, reproductivo y de cuidados.

\section{Bibliografía}

Alberdi, Juan Bautista (1963) [1853] Bases y puntos de partida para la organización politica de la República Argentina. Santa Fe: Castellví.

Casaus Arzú, Marta Elena (1992) Guatemala: Linaje y racismo. San José: Facultad Latinoamericana de Ciencias Sociales.

Casaus Arzú, Marta Elena (2008) Genocidio: ¿máxima expresión del racismo en Guatemala? Guatemala: F\&G Editores.

Casaus Arzú, Marta Elena (2015) "El juicio por genocidio contra el pueblo maya Ixil: del recuerdo a la recuperación de la memoria colectiva de los pueblos indígenas a raíz del conflicto armado en Guatemala (19792013)" en alter/nativas. No. 5. Disponible en: https://alternativas.osu. edu/es/issues/autumn-5-2015/essays/casaus.html (consultado el 24 de noviembre de 2019). 
Casaus Arzú, Marta Elena y Marisa Ruiz Trejo (2017) "Procesos de justicia y reparación: el caso 'Sepur Zarco' por violencia sexual, violación y esclavitud doméstica en Guatemala y su sentencia paradigmática para la jurisprudencia internacional" en Pacarina del Sur. Año 8, No. 30, enero-marzo de 2017. Disponible en: http://pacarinadelsur.com/ home/indoamerica/1436-procesos-de-justicia-y-reparacion-el-casosepur-zarco-por-violencia-sexual-violacion-y-esclavitud-domesticaen-guatemala-y-su-sentencia-paradigmatica-para-la-jurisprudenciainternacional (consultado el 24 de noviembre de 2019).

Castellanos Moya, Horacio (1997) El asco. Thomas Bernhard en El Salvador. Barcelona: Tusquets.

Chéves, Adelaida (1887) Llave de oro. Compendio de economía doméstica para uso de las jóvenes centro-americanas. Nueva York: La Revista Ilustrada de Nueva York.

Chivalán, Marco, (2015) "Nodrizas e infantes a finales del siglo XVIII en Guatemala o biotanatopolítica de gestión de la lactancia" en AVANCSO, Sexo y raza. Analíticas de la blancura, el deseo y la sexualidad en Guatemala. Guatemala: Asociación para el Avance de las Ciencias Sociales en Guatemala (AVANCSO). pp. 171-211.

Comisión de Esclarecimiento Histórico (CEH) (1999) "Violencia sexual contra la mujer" en Guatemala. Memoria del silencio. Tomo III: Las violaciones de los derechos humanos y los hechos de violencia. Guatemala: Comisión de Esclarecimiento Histórico. pp. 13-57.

Crosby, Alison y M. Brinton Lykes (2011) "Mayan Women Survivors Speak: The Gendered Relations of Truth-Telling in Postwar Guatemala" en The International Journal of Transitional Justice. Vol. 5, pp. 456-476.

Crosby, Alison, M. Brinton Lykes y Brisna Caxaj (2016) "Carrying a heavy load: Mayan women's understandings of reparation in the aftermath of genocide" en Journal of Genocide Research. Vol. 18, no 2-3, pp. 265-283.

Cumes Simón, Aura Estela (2014) "Cultura de servidumbre y trabajo en casa particular. A propósito del Día Internacional del Trabajo, I” en Comunidad de Estudios Mayas. Espacio de Pensamiento Crítico y Plural. Disponible en: http://commaya2012.blogspot.com/2014/05/culturade-servidumbre-y-trabajo-en_3.html (consultado el 24 de noviembre de 2019). 
Cumes Simón, Aura Estela (2014) La "india" como "sirvienta". Servidumbre doméstica, colonialismo y patriarcado en Guatemala. Tesis de doctorado en Antropología, Centro de Investigaciones y Estudios Superiores en Antropología Social, México, octubre de 2014.

Cumes Simón, Aura Estela (2015) "La casa como espacio de 'civilización"” en Séverine Durin, María Eugenia de la O y Santiago Bastos (coords.), Trabajadoras en la sombra. Dimensiones del servicio doméstico latinoamericano. México: Centro de Investigaciones y Estudios Superiores en Antropología Social, Escuela de Gobierno y Transformación Pública, Tecnológico de Monterrey. pp. 371-397.

Cumes Simón, Aura Estela (2019) 'La 'india' como 'sirvienta'. Servidumbre doméstica, colonialismo y patriarcado en Guatemala” en Ana Silvia Monzón (coord.), Antología del pensamiento crítico guatemalteco contemporáneo. Buenos Aires: Consejo Latinoamericano de Ciencias Sociales. pp. 569-606.

Dore, Elizabeth (2006) Myths of Modernity. Peonage and Patriarchy in Nicaragua. Durham: Duke University Press.

Dosal, Paul (2005) El ascenso de las élites industriales en Guatemala: 18711994. Guatemala: Fundación Soros.

Equipo de Estudios Comunitarios y Acción Psicosocial (ECAP) (2016) "Sepur Zarco. El camino de las mujeres hacia la justicia” en Separata, $A$ seis meses de la Sentencia Condenatoria. Ciudad de Guatemala.

Ehrenreich, Barbara y Deirdre English (2005) For Her Own Good. Two Centuries of Experts' Advice to Women. Nueva York: Second Anchor Books.

Foucault, Michel (2008) The Birth of Biopolitics. Lectures at the Collège de France, 1978-1979. Nueva York: Palgrave Macmillan.

Fulchirone, Amandine et al. (2009) Tejidos que lleva el alma. Memoria de las mujeres mayas sobrevivientes de violación sexual durante el conflicto armado. Guatemala: Equipo de Estudios Comunitarios y Acción Social, Unión Nacional de Mujeres Guatemaltecas y F\&G Editores.

González Izás, Matilde (2014) Modernización capitalista y violencia en Guatemala (1750-1930). México: El Colegio de México.

Grandin, Greg (2004) "Can the Subaltern Be Seen? Photography and the Affects of Nationalism" en Hispanic American Historical Review. Vol. 84, no 1 , pp. 83-111. 
Hirschmann, Albert O. (1997) The Passions and the Interests. Political Arguments for Capitalism Before Its Triumph. Princeton: Princeton University Press.

Jiménez, Ricardo (1895) "Discurso ante el Congreso" en Informe de la Inspección General de Enseñanza, 1894-1895. San José: Tipografía Nacional.

Larrave de Castellanos, Pilar (1895) Economía doméstica, para uso de las jóvenes centroamericanas. Ciudad de Guatemala: Tipografía Americana.

Liano, Dante (2004) El hijo de casa. Barcelona: Roca Editorial.

Méndez, Luz y Amanda Carrera Guerra (2014) "Las mujeres de Sepur Zarco" en VV.AA., Mujeres indigenas: clamor por la justicia. Violencia sexual, conflicto armado y despojo violento de tierras. Guatemala: Equipo de Estudios Comunitarios y Acción Psicosocial. pp. 45-77.

Milla, José (1882) [1861] "Las criadas" en Cuadros de costumbres guatemaltecas. Guatemala: Tipografía El Progreso. pp. 161-170.

Miller, Zinaida (2008) "Effects of Invisibility: In Search of the 'Economic' in Transitional Justice" en The International Journal of Transitional Justice. Vol. 2, pp. 266-291.

Montúfar, Lorenzo (1887) Apuntamientos sobre Economía Política. Guatemala: Tipografía La Unión.

Nelson, Diane (1999) "Gendering the ethnic-national question. Rigoberta Menchú jokes and the outskirts of fashioning identity" en $A$ Finger in the Wound. Body Politics in Quincentennial Guatemala. Berkeley: University of California Press.

Orellana, Carlos (1997) Historia de la educación en Guatemala. Guatemala: Universidad San Carlos de Guatemala.

Palma Murga, Gustavo (coord.) (2012) Romper las cadenas. Orden finca y rebeldía campesina: el proyecto colectivo Finca La Florida. Guatemala: Asociación para el Avance de las Ciencias Sociales.

Polanyi, Karl (1989) La gran transformación. Crítica del liberalismo económico. Madrid: Ediciones de la Piqueta.

Rosser, Emily (2007) "Depoliticised Speech and Sexed Visibility: Women, Gender and Sexual Violence in the 1999 Guatemalan Comisión para el Esclarecimiento Histórico Report" en The International Journal of Transitional Justice. Vol. 1, pp. 391-410.

Sanford, Victoria (2008) Guatemala: del genocidio al feminicidio. Guatemala: 
F\&G Editores.

Sanford, Victoria, Sofía Duyos y Kathleen Dill (2016) "Sexual violence as a weapon during the Guatemalan genocide" en Sanford, Victoria; Stefatos, Katerina y Cecilia M. Salvi, Gender Violence in Peace and War. States of Complicity. New Brunswick: Rutgers University Press. pp. 34-46.

Sarmiento, Domingo Faustino (1999) [1845] Facundo. Madrid: Cátedra.

Segato, Rita Laura (2003) Las estructuras elementales de la violencia: ensayos sobre género entre la antropología, el psicoanálisis y los derechos humanos. Buenos Aires: Universidad Nacional de Quilmes.

Sarmiento, Domingo Faustino (1999) [1845] Facundo. Madrid: Cátedra.

Segato, Rita Laura (2014) "Las nuevas formas de la guerra y el cuerpo de las mujeres" en Revista Sociedade e Estado. Vol. 29, no 2, pp. 341-371.

Sarmiento, Domingo Faustino (1999) [1845] Facundo. Madrid: Cátedra.

Segato, Rita Laura (2016) Peritaje Antropológico de Género. Causa del Caso Sepur Zarco, municipio de El Estor, departamento de Izabal. Disponible en: http://www.unsam.edu.ar/pensamientoincomodo/files/Peritaje $\% 20$ Antropol\%C3\%B3gico\%20de\%20G\%C3\%A9nero.\%20Causa\%20 del\%20Caso\%20Sepur\%20Zarco..pdf (consultado el 20 de mayo de 2020).

Silva Santisteban, Rocío (2008) El factor asco. Basurización simbólica y discursos autoritarios en el Perú contemporáneo. Lima: Pontificia Universidad Católica del Perú, Instituto de Estudios Peruanos, Universidad del Pacífico.

Smith, Adam (1999) [1776] The Wealth of Nations. Books I-III. Nueva York: Penguin Books.

Tischler Visquerra, Sergio (1998) Guatemala 1944: crisis y revolución. Ocaso y quiebre de una forma estatal. Guatemala: Universidad San Carlos de Guatemala, Benemérita Universidad Autónoma de Puebla.

Velásquez Nimatuj, Irma Alicia (2019) "La justicia nunca estuvo de nuestro lado". Peritaje cultural sobre conflicto armado y violencia sexual en el caso Sepur Zarco, Guatemala. Vitoria: Universidad del País Vasco.

Zamora Chamorro, Marcela (2013) Las muchachas (mediometraje documental). San Salvador: El Faro.net.

Yeves, Carlos (1889) Economía doméstica y labores. Madrid: Librería de la Viuda de Hernando y Cía. 